\title{
PLACE-MAKING AND ITS IMPLICATIONS FOR SOCIAL VALUE: A COMPARISON STUDY OF TWO URBAN SQUARES IN LONDON
}

\author{
A. ALZAHRANI, K. BORSI \& D. JARMAN \\ Department of Architecture and Built Environment, University of Nottingham, UK.
}

\begin{abstract}
This article aims to investigate the impact of place-making on the social value attached to two recently developed public squares in London. Empire and Bermondsey developments were developed with the explicit intention to have a public open space that is available for its residents and the surrounding community. Place-making supports the concept of generating places that improve the relationship between users and space, by increasing a sense of place. In this respect, social value is an intangible benefit that can be captured from places that shape community attitude and might often cater to necessary activities but is essential to everyday functions. Based on an extensive review of the literature and empirical work, this article will explore the similarities and differences between these two squares to deliver a better understanding of the reasons behind the urban design as a place-making tool in generating social values attached to physical spaces. These two squares are comparable in size, physical setting and geographical and social context providing unique contexts for socio-spatial analysis. This study follows a case- study approach. For both case studies, there are 100 surveys and 33 semi-structured interviews in total conducted with participants at the squares. Also, many site observations for this study have been taken, in both cases, at different times of the day tracking human movement, activities, spatial qualities, social interactions and spatial interrelations. The data gathered facilitate explicit connections between the behavioural, perceptual and social dimensions. These relationships are essential to understanding the role of urban design in adding social value. This study demonstrates the complex nature of the generation of social value in urban spaces through place-making.
\end{abstract}

Keywords: place-making, public space, social value, urban design.

\section{INTRODUCTION}

Place-making is a concept that emerged after it became clear that it was necessary for the urban design to consider the cultural, social, economic, political and spatial factors as well as the importance of people's activities and perceptions of urban public places [1]. It supports the concept of generating places that improve the relationship between users and space, by increasing a sense of place [2]. The social dimension developed through a greater focus on the use, activities and perceptions of space [3, 4]. The quality of urban public space is affected by effective place-making and the visual appearance that impacts on its use [5]. The aim of place-making is to combine the 'the hard city' of spaces and buildings and 'the soft city' of activities and people [1]. Therefore, the generation of successful places requires diversity, activities and the capability of the physical milieu to enable and boost those activities and functions [6]. Good quality design, security, cleanliness, attractiveness and an inclusive place with good connectivity to the surroundings are required for place-making, together with improving social interaction to produce a stronger community [7]. 
In accordance with this, this article aims to investigate the development of the social value attached to two recently developed public squares in London as a result of place-making. Bermondsey and Empire developments were developed with the explicit intention to have a public open space that is available for its residents and the surrounding community. Based on an extensive review of the literature and empirical work, this paper will explore the similarities and differences between these two squares to deliver a better understanding of the reasons behind the place-making in generating the social values through the squares of two mixed-use development in London.

\section{PLACE-MAKING AND SOCIAL VALUE OF URBAN SPACES IN LONDON}

Place-making is concerned with the design of urban public spaces as physical and aesthetic entities as well as behavioural settings. The term was used to refer to the process of generating attractive places for people. The root of the concept emerged in the 1960s when ideas by Jacobs and Whyte had emphasised the need for good designing of cities for people [8]. The trend became popular among planners, developers and urban scholars in the 1970s. With the growing trend of place-making, substantial attempts have been established to identify the quality of successful urban places.

The historical and contemporary processes of shaping the place had been through different natural and cultural context, which have a significant effect on the nature and qualities of space [9]. The continuing trend towards characterising place-shaping processes in the United Kingdom from the late 1990s is leading strongly in the provision of contemporary spaces [10]. The Urban Task Force was set up to identify the reasons for the urban decline and launch a vision to promote successful regeneration and place-making, and to think about urban design not only from the start of planning but also during the development process [11]. However, the new spaces in the 1980s had been shaped by the private sector effectively conceiving the urban square as the centre of urban large-scale development and ignoring public spaces elsewhere [9]. The vision of the urban renaissance was to see an increasingly active role of the public sector as a promoter, partner, or even direct provider in the provision of public space. During the late 1990s, problems were the funding of largescale and high-quality investment in public space as well as the abandonment of the mayor's 100 World Squares project. London benefited from small-scale partnerships and private intuitive projects [10]. This vision of public space from the private sector provision was reflected in London's planning policies and initiatives. Ken Livingstone's 100 public spaces programme was attempted in 2002 to promote and make new public spaces across London. He thought that the quality of public space should have a direct impact on London's beauty, connectivity and safety. Carmona and Wunderlich indicated that the 100 Space strategy showed the limitation of the Mayor's power in the local distribution of the projects in the public realm [12]. They also showed that there were difficulties with public space schemes even when the Mayor had direct responsibility. Dealing with such an issue, the London Plan sought to promote the city's growth within its boundaries without encroaching on open spaces. At the same time, they sought to make London a more attractive, well-designed and green city [13]. This plan aims to develop the quality of London through enhancing the public realm, public space and waterways. It also emphasises the importance of creating new public spaces in such a compact city [14]. However, the quality of the public realm has a bigger vision than merely competing globally or satisfying Londoners' pride. It has a 'significant influence on the quality of life because it affects people's sense of place, security and belonging' p.281 [15]. When looking at such initiatives and 
policies reflected in the provision of open public spaces, it illustrates that there are implicit relationships between the settings of the geographic structures in inner London. There are some common characteristics that can be distinguished by looking at these public spaces. In particular, spaces in inner London are located within mixed-use developments or multifunctional areas. Thus, there is more diversity in term of characteristics and uses. As a result, these spaces tend to be more inclusive and sociable with a greater degree of adaptability [16].

According to Macmillan [17], social value has coloration with the encouragement provided to residents by places and buildings, which facilitates interaction in ways that lead to trust, shared understanding, shared values and supportive behaviours. The social value of public space depends on the input that can be provided to people in terms of increasing people's attachment to their local life, interacting face to face with others and people's memories of sites. Streets and markets that reflected hard spaces are extremely beneficial to many people as green spaces such as parks [18]. Therefore, social value can be a part the urban identity where these social behaviours are controlled by the design of these public spaces or developed along with it. Walmsley [19] claimed that there is a relationship between the environmental perception of a place and its social behaviours. He also argued that human behaviours are developed by inter-relations within the environment as well as by urban environment that can be the foundation of this development. Social value emerges when people have shared interests that can join them with one another [17]. Therefore, the importance of the role of the public realm and associated semi-public spaces is emphasized by Montgomery [20] which provides the territory for social interactions and a substantial part of a city's transaction base such as the market square, the shop frontage, the street vendor and the sidewalk café. It is advisable to be linked and connected to the community. Life and space of individuals could lead to active connections with culture, society, community, economy and the whole universe. However, for people to become attached to their area, there are basic requirements that space must achieve for it to be meaningful. For instance, a place should be recognizable and visible for people to see the meaning in the setting. Emphasizing relationships and social significance of the site can reflect its physical qualities [21].

\section{CASE STUDY APPROACH}

A case study approach was chosen as a viable tool for gathering qualitative and quantitative data. Selecting the case studies is an important part of this research. The case studies were selected after an in-depth review of many mixed-use developments in central London. The two cases adopted for this study meet the following indicators. (1) They are both mainly residential blocks, allowing us to examine the impact on residents and the local community within the development. (2) The volume of each mixed-use development is significant enough to produce a practical effect on the level of the surrounding neighbourhood. (3) Both mixeduse developments include a public open space that is available to its residents and the surrounding community. (4) Both cases reflect the importance of urban design policy and planning, following the Urban Task Force report. (5) The cases take different approaches for developing the scheme. (6) The size of the development is between 100 to 800 units; this enables a meaningful comparative assessment of the cases (Table 1). Even though it is not an easy mission to identify the suitable pair, Empire Square (ES) and Bermondsey Square (BS) pair were selected to do this study (Figs 1 and 2). They are both located in London Borough of Southwark. 


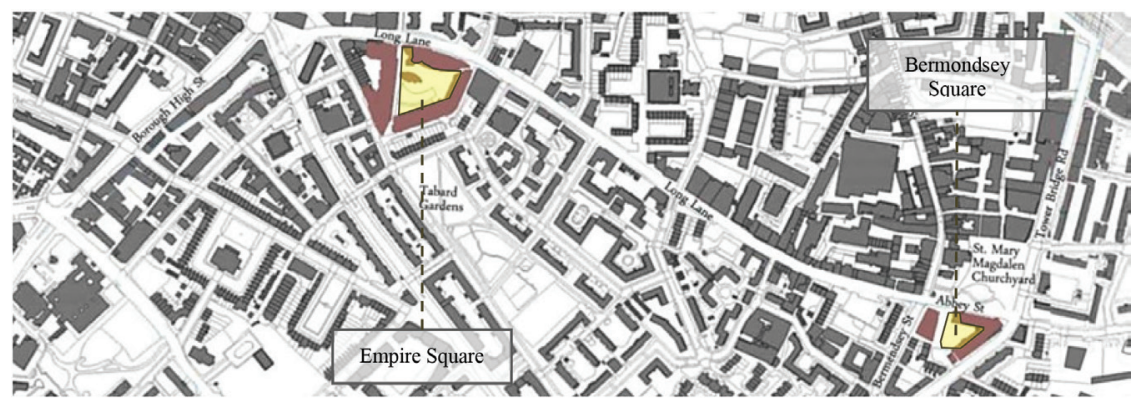

Figure 1: The location of ES and BS (Obtained from 2012 OS Mastermap).

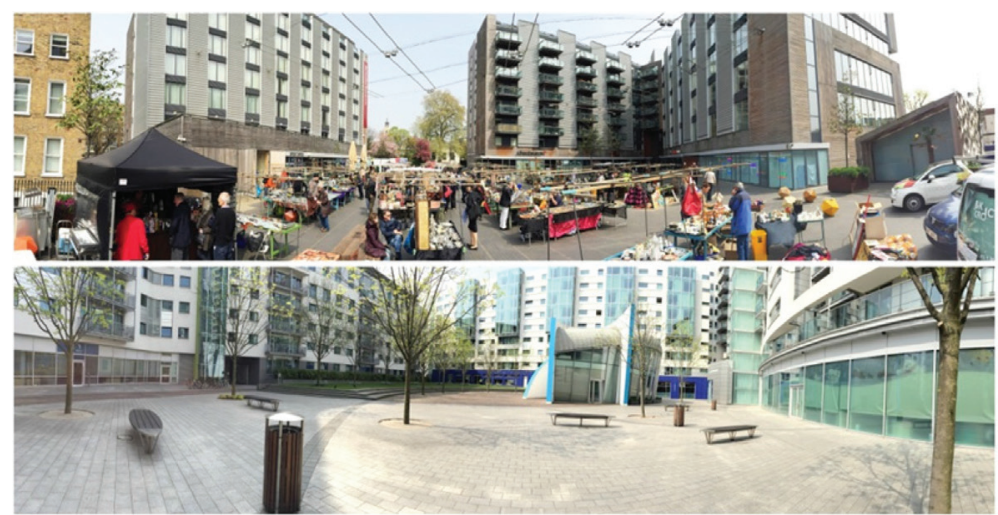

Figure 2: B.S (top), the antique market had taken place on Friday the 24th of April 2015. E.S (bottom), Even though it is sunny noon on the same day, the square appears empty. (Images: the author)

\subsection{Background of the Case Studies}

\subsubsection{Case 1: EMPIRE square}

ES is a residentially led development in the historic district of Southwark, located at the end of Borough High Street. The site was used industrially, including as a good's depot, until the London Borough of Southwark saw possibilities for its development. They emphasised that high quality needs to be addressed in this project. An initial approval was granted for 270 residential units of a gated community development with no public access. However, Berkeley Homes, the developer, sought to increase the density to 572 mixed-tenure units. Thus, they saw the potential of a new public square and affordable units by giving around $33 \%$ of the site to public use. The new public square was a price worth paying for the additional units they got [22]. The project was completed in 2007 and won the Housing Design Awards and CABE Gold Award [23].

\subsubsection{Case 2: Bermondsey square}

The Southwark Council and Igloo Regeneration Partnership worked together to redevelop BS as part of an economic, social, environmental and physical intervention. The vision of Bermondsey is set around a new square that hosts the Bermondsey Antique Market. A 
Table 1: The characteristics of the selected case studies.

\begin{tabular}{|c|c|c|}
\hline & Empire Square & Bermondsey Square \\
\hline Location & London Borough of Southwark & London Borough of Southwark \\
\hline Usage & $\begin{array}{l}\text { Offices, health club, retail units and } \\
\text { residential. }\end{array}$ & $\begin{array}{l}\text { Offices, retail units, residential, hotel, } \\
\text { bar, restaurant, cinema and café. }\end{array}$ \\
\hline Developer & Berkeley Homes & Igloo Regeneration \\
\hline Design & Rolfe Judd & Munkenbeck + Partners Architects \\
\hline Size & 572 units \& commercial retail space & $\begin{array}{l}76 \text { units, a 79-bed boutique hotel \& } \\
\text { commercial retail space }\end{array}$ \\
\hline Occupiers & $\begin{array}{l}\text { Gym, retails, nursery, NHS facility, } \\
\text { grocery store and office uses }\end{array}$ & $\begin{array}{l}\text { Hotel, restaurants, café, bar, cinema, } \\
\text { grocery store and office uses }\end{array}$ \\
\hline Completed & 2007 & 2008 \\
\hline \multicolumn{3}{|l|}{ Site Plan } \\
\hline & Obtained from www.ro & Obtained fron \\
\hline
\end{tabular}

farmer's market, exhibition and community-related outdoor events are being scheduled and held at BS to help increase social interaction and enliven the space. The development is at the end of Bermondsey Street and intersects with the less-gentrified Tower Bridge Road, the outer limit of the city centre. The square is intended by the developer and council to be the heart of Bermondsey [24].

\section{DATA GATHERING TOOLS}

There are several different research methods that have been developed and employed in this study, which form one comprehensive methodology. Therefore, the knowledge claim for both case studies from all the methods will provide qualitative and quantitative data as well. Two different trips have been undertaken to obtain the data for this study. For both case studies, there are 100 surveys and 33 semi-structured interviews in total conducted with participants at the squares. The participants are occupiers, managing agents, residents and everyday users. All 100 participants have been asked to answer face-to-face survey that takes about five to eight minutes to complete, and 33 participants have been invited to spend 10 minutes of face-to-face interviews. On the first trip, the data was gathered from questionnaires from both sites. It has developed supporting knowledge for the social analysis of the study. The findings of each case are demonstrated in various charts and tables to express a valuable range of knowledge to promote the understanding of the outcomes of the observational and socio-spatial analysis work. The 33 semi-structured interviews take place to eliminate the limitation of some data that occur from the questionnaire in the first trip. The 
way semi-structure interviews are constructed for this second trip of conducting data is to help cope with the lack of understanding with regards the complexity of vitality among some participants in the first trip of data collection. Therefore, the questions of the second trip are set for the aim of the study, in a way that can encourage the participants to reveal their opinions directly. At the same time, the primary goal of this interview is not to measure the perception of users but rather to recognize the social, spatial value relevant to the urban design. Also, many site observations for this study have been taken, in both cases, at different times of the day. The unobtrusive observational approach was used to track human movement, activities, spatial qualities, social interactions and spatial interrelations. The pedestrian traffic movement and static activities such as gatherings and meetings are recorded on the basis where individuals sit, meet and move. This research will be analysed in the comparative analysis approach that aims to minimize the deficiency of research work. It can also generate findings that support and benefit the overall outcome of the research. Therefore, a comparative study is considered to be the ideal approach for such a study due to its understanding of the socio-spatial inter-relation and social values [25]. The comparative analysis approach will allow the researcher to assess and evaluate the theories and test the outcomes of the study as well.

\section{EMPIRE SQUARE: PLACE-MAKING PROCESS}

It is hard for the conducted data from the analysis work (social, perceptual and behavioural) to be a stand-alone source that can generate further recommendations or discussions. This article produces analytical knowledge that has established a strong connection between the three dimensions of this article (Fig 3). The data shows that ES exists in an area with a great variety of age, scale, urban fabric and style of buildings. The eight-storey development fitted better into the scenic context and the skylines of the surrounding five- and six-storey buildings. The development fits comfortably into the current street scene physically but struggles to deliver social benefits to its surroundings. This is because although the development integrates well with its surroundings, the restrictions at the entrances and the presence of gates reduce the connectivity. These factors decrease any real impact regarding adding social value to ES community.

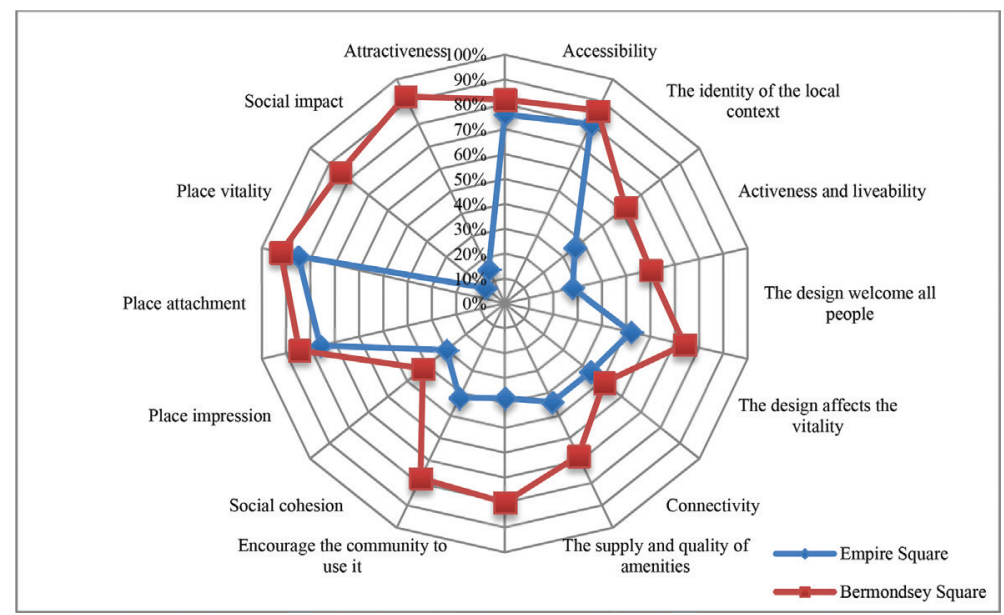

Figure 3: Social and perceptual analysis of both case studies. 
Despite the concept of ES as a public resource, space was built to serve the development rather than the local population. The loss of interest in the edge of the street, limited access and converting the square to a quiet space contribute directly to minimizing its potential to add social value. At an early stage of the scheme design, ES was intended as a regeneration development to boost the local area through mixed-use development. Both the community and local authorities had high expectations from the potential outcomes of ES. However, the level of control within space alongside the presence of gates limits users from using the space comfortably and minimizes the direct impact upon surroundings. According to Rolfe Judd, the designer of the scheme, as cited in [26], the project was influenced by the surrounding park and square development, which is fundamental to the City of London. His intention was to increase the footfall and allow users through the square by injecting life into the square with facilities that serve the local community and generate activity. However, the development process of ES changed over time and forced the designer to minimize the degree of closure with the surrounding area with over-design of the public space. Nevertheless, this particular development failed to achieve the vision of ES, which was to add social benefit among other benefits for its community.

Most of the activities that take place at ES are related to walking activities. The data gathered shows the association between these activities and the awareness of the site. It also shows a high percentage of users $(62 \%)$ who come to the square alone, which means that the square is not a stimulating environment for activities or for social interaction. The square acts simply as a transit pathway that is used by people as part of their daily routine. This limitation of use could be seen as a result of the way the place is being controlled. Even though participants agree that ES is accessible (80\%) and well presented for its potential occupiers, users suffer from the absence of stimulations, which would generate meaning for the place. Although ES is considered a visually pleasant place, it is also regarded as an empty space by its users. Activities and social interaction must appear in such a case to cope with the placelessness of ES and to satisfy users' desire. According to the data gathered, ES was created primarily for the residents' needs with the boosting of social benefits within its context as a secondary concern. As a result, users see this area as private for residents only while the residents themselves do not use the space.

The data gathered also shows a positive response regarding the place impression and place attachment in the case of ES. However, the square fails to satisfy users by providing a vibrant place. In addition, ES minimizes the social impact on its users, and does not tie the community together by contributing strong social cohesion. It implies weak connections and relationships between the different social units within this context, such as individuals and groups. On the other hand, the attachment to the place is strong among the users of ES. This suggests that the square significantly contributes to the binding of individuals and place together. The square becomes meaningful and recognizable to users who use the place individually, which delivers meaning to them. The data reveals that the square shows a complete awareness and acceptance among its users regarding using it only for necessary activities, starting a profound relationship with them while they are isolated from each other.

\section{BERMONDSEY SQUARE: PLACE-MAKING PROCESS}

In the case of BS, the presence of the antique market supports BS by linking the development with neighbouring businesses and residential communities. The existence of the antique market has an impact on the community and the cultural and commercial aspects of the area, all of which have brought authenticity to the development. The most substantial benefits from 
such a market besides selling goods are that they maintain the historical links, a sense of place and local identity [27]. The BS Community Fund is in charge of managing a comprehensive programme of outdoor events and activities held at BS to help increase social interaction and enliven the space.

Unlike ES, the design of BS offers an adaptable open public space that can host weekend or seasonal events and markets. The design of space consists of one single space surrounded by wooden benches and abstract sculptures along the edges of the square. The square is well integrated into the surroundings because it allows visual and physical accessibility and provides amenities and activities for the community. This integration with the surroundings increases footfalls and enables users to walk through the square and increase the time spent there by users. The vision of the different stakeholders of this development is to enliven the area and provide land use that supports the needs of the local community. The designer of BS was keen to deliver value to the area by including a new public space that will become a destination in itself for locals and visitors alike during the lifetime of the square.

The data gathered demonstrates how most users are attracted to what the square provides in term of activities, events and amenities. The square is easy to find because of the way the development fits into the context and integrates with the surroundings to attract more users and visitors. BS shows promising findings regarding the way it provides intangible benefits beyond its surrounding community because of the historical value of the antique market, which encourages people to come to the square more often. The square generates place attachment among its users within the context of Bermondsey area while being an attraction for Londoners and visitors alike due to the provision of amenities, leisure activities and events. The quality of the public space in the area was improved by BS as a well-designed public space and by the outdoor activities that appeared alongside the presence of the new public space.

BS is perceived as a large open space by participants because of the degree of openness and accessibility, which influences the vitality of the place along with the provision of activities. It implies an association between how people perceive the public space and make use of it. The impression of expansion of space could be because of the time that the questionnaires were conducted, which was during weekdays outside the market days. A different view of space was offered by stall-holders at the market. It was perceived as being less wide than before the new development was built. Participants thought that the tall buildings, which surround the market, has restricted the openness of the place while the market looks smaller than it should be. The comparison of those perceptions within BS reveals the historical image that was developed during time among users and occupiers. It reveals their concerns and desires of the place. They are keen to maintain the market as it used to be. Accessibility is another quality that is positively associated with BS use. It allows users to walk through the square without restriction and benefit from using the shops and amenities.

In the case of BS, the data gathered shows a positive response regarding the place impression and place attachment. The place offers a meaningful site for local users and generates activities that can involve their families and friends as well. Also, BS maximizes the social impact on its users by the provision of accessibility and activities. The square also links the community together by contributing strong social cohesion. The square is connected to the surrounding neighbourhood, generating life and forming a strong sense of a place. For instance, the presence of the antique market, farmers' market and Vitrine Gallery encourages residents and the local community to benefit from local businesses and open spaces. Southwark Council provides an environment in the Bermondsey area in which a variety of uses and 
housing types can be established. The area is allowed to be developed at its own pace and in its own style [28].

\section{DISCUSSION}

There is no hesitation in including social value as a common attribute of the two squares. However, the question is whether they are similar in terms of developing social value through place-making. The social value of the place, in the case of ES, can be captured by the growing nature of place from the experience of use. The character of the place, part of which is defined by the activities of the many users who walk through, stay, use, visit or even avoid the place, leads to possibilities rather than determining the outcomes. The primary goal of place-making is to combine the physical setting of spaces and activities to support social interactions to produce a stronger community. The over-design of the public space in the case of ES while neglecting the provision of activities fails to achieve the vision of the development, which was to add intangible benefits among other benefits for its community. On the other hand, the initiatives by the management of BS have led to the integration of space with the surrounding context and meet the needs of its residents and the local community. The data demonstrate good socio-spatial relations between residents and the place, which is supported by the variety and constancy of activities and events. The role of the place in delivering intangible benefits to the community occurs as a result of the shift in public policy, moving away from physical aspects such as cleaner, safer, greener agenda [29] and towards strengthening a sense of community instead of merely emphasising its tangible aspects. The participation of users, the square's occupiers and other businesses around Bermondsey Street have contributed to BS's success. The approach has allowed the community to get involved in developing their public spaces according to their own ideas and timeline. This tactic, which is giving space and time to the local residents to participate in the development of the area, is a doubleedged sword and suggests that regeneration is a long-term process. Some of the community will get positively involved and cooperate with the different stakeholders to accomplish the ultimate goal for their neighbourhoods while some others will lean on the public sector without getting involved. However, the association with people, places, activities and events support the sense of belonging to the community [30]. Social value is an intangible benefit that can be gained from places that shape the community's attitude that helps to create an identity for the neighbourhood.

\section{CONCLUSION}

As a result of place-making, the social value of urban places makes them necessary in our cities due to their involvement with people needs. The quality of people's life can be affected by urban public spaces. Therefore, they must provide people with both tangible and intangible benefits; otherwise, parts of the society could be pushed out of the public realm, which will result in severe limitations in the daily lives of individuals. In conclusion, the emergence of social value in urban places does not work in similar procedures. Therefore, the provision of places should not rely on the aesthetic aspects alone minimizing the activities and functions that enable and boost social values. The balance between both aspects should occur in places that spread all over our cities. The outcomes of this research suggested that placemaking add value by balancing the generation of space and behavioural settings to deliver social benefits to our communities. The findings of this article are leading material for future research such as assessing social value by indicators to identify areas where enhancements are desired. 


\section{REFERENCES}

[1] Carmona, M., Tiesdell, S., Heath, T. \& Oc, T., Public Places Urban Spaces, Oxford: Architectural Press, 2010.

[2] Aravot, I., Back to phenomenological placemaking. Journal of Urban Design, 7(2):201-212, 2002.

http://dx.doi.org/10.1080/1357480022000012230

[3] Lynch, K., The Image of the City, Harvard U.P; Oxford U.P, 1960.

[4] Jacobs, J., The Death and Life of Great American Cities, Vintage Books, 1961.

[5] Gehl, J. \& Matan, A., Two perspectives on public spaces. Building Research \& Information, 37(1): pp. 106-109, 2009. http://dx.doi.org/10.1080/09613210802519293

[6] Lombard, M., Constructing Ordinary Places: Place-Making in Urban Informal Settlements in Mexico, Progress in Planning, 94, pp. 1-53, 2014. http://dx.doi.org/10.1016/j.progress.2013.05.003

[7] Dempsey, N. \& Burton, M., Defining place-Keeping: The Long-Term Management of Public Spaces, Urban Forestry \& Urban Greening, 11(1), pp. 11-20, 2012. http://dx.doi.org/10.1016/j.ufug.2011.09.005

[8] PPS, What is Placemaking? cited, 2015.

[9] Carmona, M., Re-theorising contemporary public space: a new narrative and a new normative. Journal of Urbanism: International Research on Placemaking and Urban Sustainability, pp. 1-33, 2014.

[10] Punter, J., Urban Design and the British Urban Renaissance, Routledge, 2010.

[11] Force, U.T., Towards an Urban Renaissance, London E \& FN Spon, 1999.

[12] Carmona, M., The Place-shaping Continuum: a Theory of Urban Design Process. Journal of Urban Design, 19(1), pp. 2-36, 2014. http://dx.doi.org/10.1080/13574809.2013.854695

[13] RIBA, Delivering the Vision, RIBA London Response to the Draft London Plan, RIBA Publication, pp. 1-14, 2014.

[14] GLA, The London Plan: Spatial Development Strategy for Greater London Consolidated with Alterations since 2004. Sustainable development, 39, p. 2, 2008.

[15] GLA, The London Plan: Spatial Development Strategy for Greater London Consolidated with Alterations since 2011, ed. G.L. Authority, Greater London Authority: London, 2015.

[16] Carmona, M. \& Wunderlich, F.M., Capital Spaces: The Multiple Complex Public Spaces of a Global City, Taylor \& Francis., 2013.

[17] Macmillan, S., The Value Handbook: Getting the Most from Your Buildings and Spaces, CABE: London, 2006.

[18] Cattell, N.D.V., Gesler, W. \& Curtis, S., Public Spaces, Social Relations and Well-Being in East London, Joseph Rowntree Foundation: Bristol, 2006.

[19] Walmsley, D.J., Urban Living: The Individual in the City, Longman Scientific \& Technical Essex, 1998.

[20] Montgomery, J., Making a city: urbanity, vitality and urban design. Journal of Urban Design, 3(1), pp. 93-116, 1998. http://dx.doi.org/10.1080/13574809808724418

[21] Carr, S., Francis, S, Rivlin, L. \& Stone, A., Public Space, Cambridge University Press, 1993. 
402 Urban Regeneration and Sustainability

[22] Carmona, M. \& Wunderlich, F.M., Capital Spaces, the Multiple Complex Public Spaces of a Global City, Routledge, 2012.

[23] Keddie, J., The Square and the Gardens: Experiences of Public Space in Gentrifying London, 2010.

[24] Stewart, D. Operation Hip: Igloo's Bermondsey Square, [cited 2014 17/03/2014], 2009, available at http://www.building.co.uk/operation-hip-igloos-bermondseysquare/3141368.article

[25] Ragin, C.C., The Comparative Method: Moving Beyond Qualitative and Quantitative Strategies, University of California Press, 1989.

[26] Marshall, S., Tabard Square is a major mixed-use development by Rolfe Judd within walking distance of the City London, Architecture Today, 177, p. 18, 2007.

[27] Solnit, R. \& Schwartzenberg, S., Hollow City: The Siege of San Francisco and the Crisis of American Urbanism, Verso, 2002.

[28] Schwab, A., Communities in Transition: Bermondsey, Future of London's Communities in Transition, 2013.

[29] UK-Government, Living Places: Cleaner, Safer, Greener, ed. D.P. Minister, London, 2006.

[30] Lofland, L.H., The Public Realm: Exploring the City's Quintessential Social Territory, Transaction Publishers, 1998. 